\title{
A Digital Education Made Personal: An Examination of the Impact of Personalized Business English Education at Bayer Korea
}

\author{
Nam Hee Kim \\ goFLUENT Korea, Seoul, Korea
}

Objectives: Many companies have transitioned into digital education, allowing learners to select a learning time, place, and curriculum that best suits them. In this case report, we share cases of individuals and businesses selecting and learning content that fit their strategies and needs, rather than taking part in a general training path.

Methods: The contents of individualization and personalization are different. Individualization refers to learning only the material that one prefers; personalization is not only about one's preferred content, but it also refers to improvements in Skillsoft technology by including additional content. This study analyzes the impact of providing personalized content to office workers.

Results: Continuous learning, personal satisfaction, and fulfillment of individual learners were higher when a personalized training path was provided, compared to the fixed and general business English training path. This helped learners improve their confidence in using business English for their work as they were able to apply it immediately; furthermore, it helped them save time.

Conclusions: Office workers value time more than anyone else. When they make time to study business English, efficiency is an important factor. A general and broad training path does not motivate learners. On the other hand, personalized contents based on the company's global strategy, along with personal interests, allow learners to realize the value of education in their work, motivating them to invest time into learning business English and giving them a sense of satisfaction and confidence in using it.

Key Words: Business English, Digitalized Learning, Personalized Education, Training Path, Online Education

\section{Introduction}

An enterprise operates within a continuous stream of data and information. Information sharing and delivery and feedback, which cover most of business communication, are the most

Received: May 12, 2020 Revised: Jun 29, 2020 Accepted: Jul 3, 2020 Corresponding author: Nam Hee Kim goFLUENT Korea, 134 Teheran-ro, Gangnam-gu, Seoul 06235, Korea Tel: +82-2-3437-6971, E-mail: nhkim@gofluent.com

This is an Open Access article distributed under the terms of the Creative Commons Attribution Non-Commercial License (http://creativecommons.org/licenses/ by-nc/4.0/) which permits unrestricted non-commercial use, distribution, and reproduction in any medium, provided the original work is properly cited.

Copyright $\odot 2020$ Korean Association for Business Communication. important factors in the enterprise's performance. According to Blue Source, many workers (97\%) believe that communication heavily influences the daily conduct of business (Mandelbaum, 2019). If business communication is conducted properly, everyone would be on the same page, thus reducing confusion and misunderstanding.

Moreover, in a business in which workers connect and participate through proper communication channels, productivity increases by $20 \%$ to $25 \%$ (Jouany, 2020), and, at the same time, $44 \%$ of workers want the wider adoption of internal communication tools, products, and apps for better communication (Alcala, 2015). Proper business communication improves the organizational behavior and achieves higher performance of the compa- 
ny (Pasovska \& Miceski, 2018), which, in turn, produces more profit. On the other hand, poor communication causes many problems, such as time and cost overrun, conflict, project failure, poor teamwork, misunderstanding, misinterpretation, poor risk management, and poor planning (Gamil \& Rahman, 2017).

Therefore, effective business communication is not an abstract concept that may be delegated to the background because it has no actual influence on business; rather, it is a specific principle that must be applied to business. Moreover, all companies that communicate globally use business English as their means of communication. A report from the British Council expects more than two billion people would speak fluent English by 2020. This means that about $25 \%$ of the global population can communicate freely through a language that is not their native language (Yordanova, 2019).

Companies are using online and offline face-to-face education to increase global business communication through business English. In a survey conducted in Korea in 2019, 41.7\% of the respondents answered that they spend 50,000 KRW (about 46 USD) monthly for e-learning (Statista, 2019). The survey result shows that the average amount spent on the e-learning platform is about 120,900 KRW (about 111 USD) (Statista, 2019).

In particular, demands in digital e-learning have increased rapidly as most face-to-face education was discontinued, and many companies shifted to the online education system after the outbreak of COVID-19 in 2020. Companies that have been using digital education systems have comparably less influence, while others that have no awareness or readiness for the digital education system are discontinuing it or seeking countermeasures. The higher the demand for an offline education system in Korea, the higher the risk one carries as one pursues a course of study.

Therefore, in a situation where this pandemic may continue to be a long-term concern, many companies forecast providing education through digital e-learning. Digital e-learning, regardless of restrictions in time and place, allows learners to choose the most suitable time and place for them to study. About $72 \%$ of companies believe that e-learning holds a prominent position in the area of competition (Bhat, 2020). Research from IBM shows that learners registered in e-learning courses study five times more materials compared to existing traditional courses. Also, digital learning is a more convenient, inexpensive, and attractive learning method compared to existing modes of learning (Bhat, 2020).

The purpose of this paper is to determine if business education quality and effectiveness will improve with digital e-learning content, whereas appropriate content is customized for an enterprise or an individual's business foreign language strategy. This paper examines the Korean branch of a global pharmaceutical and life science company, Bayer Korea, in its adoption of the digital e-learning program, goFLUENT.

\section{Case Description}

\section{Description of goFLUENT}

goFLUENT accelerates language learning by delivering hyper-personalized solutions that blend human interaction, technology, and globally available content on any device (Figure 1). For more than 20 years, it has been a strategic partner to Fortune 500 companies that are seeking to provide their employees with the opportunity to have an equal voice and develop language skills to communicate, collaborate, and conduct business effectively on an international scale (Figure 2). Paving the way for more than 2,000 organizations to succeed in their various markets, its programs ensure valuable and measurable returns

\section{Hyper-personalized}

Our hyper-personalized blend of technology, content, and human interaction accelerates the acquisition of language skills and builds confidence, saves time, and grows talent.

Available in English, French, German, Italian, Mandarin, Portuguese, and Spanish.

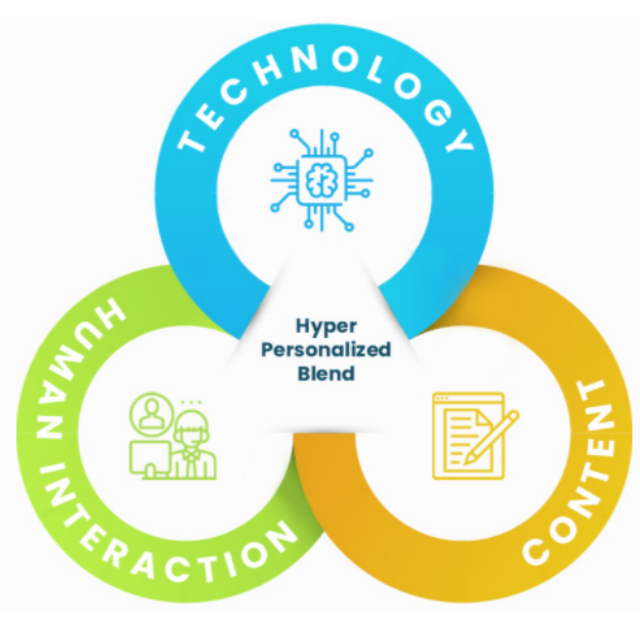

Figure 1. goFLUENT for a hyper personalized blend learning. Adapted from "goFLUENT website," by goFLUENT, $2020 \mathrm{~b}$. Copyright 2020 by goFULENT. Reprinted with permission. 


\section{Value-added services to help you hit your objectives}

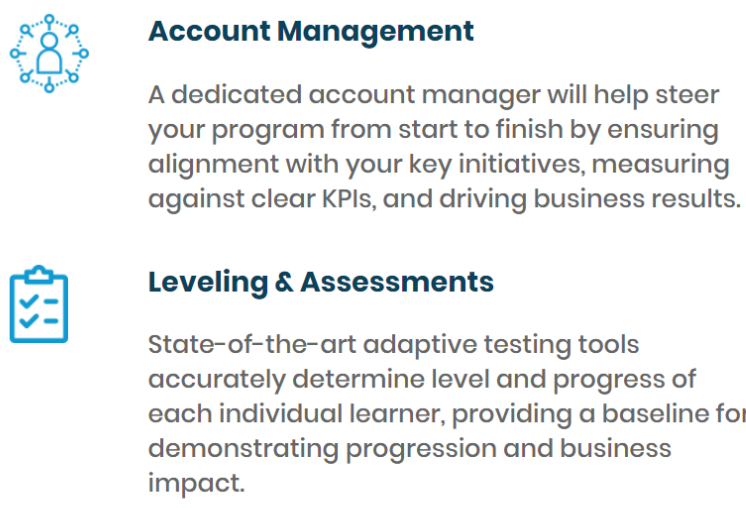

Learning Tools

\section{Learning Consultants}

Deploy globally but ensure success locally by leveraging our global learning consultants to drive user engagement and successful outcomes.

\section{Analytics \& Reporting}

Receive monthly automated emails or view ondemand reports to monitor usage and progress.

Languages

elearning Portal
Immersive language
learning experience

\begin{tabular}{|c|c|}
\hline \multirow[t]{2}{*}{$\frac{1}{889}$} & $\begin{array}{l}\text { Virtual Classes } \\
\text { Interactive small-cohort }\end{array}$ \\
\hline & language classes \\
\hline \multirow[t]{3}{*}{ 요 } & Live Lessons \\
\hline & Personalized private \\
\hline & language lessons \\
\hline
\end{tabular}

language lessons

Figure 2. Hyper-personalized blended learning of goFLUENT through technology, contents, and human interaction with learners and companies. Adapted from "goFLUENT website," by goFLUENT, 2020b. Copyright 2020 by goFULENT. Reprinted with permission.

by aligning its objectives to its clients' business, language, and communication goals.

The goFLUENT program is an enterprise that provides its users with over 7,000 business English learning resources. Many companies allow their workers to choose from this diverse set of resources to meet their needs and interests while also guiding them to study prioritized contents that are customized to their enterprise's situation and strategy. This is to provide education for the enterprise and workers to become flexible in making adjustments to the business state of affairs, which change fluidly, the role of a department, relationships with the client and the rival enterprise, etc.

Most educational institutions provided in Korea offer a general curriculum, not personalized curriculum, to office workers, and select and study the curriculum that is most suitable for them. In addition, it is recommended to complete the curriculum step by step to learn all the lessons. This can be viewed as a useful approach for students who want to study English professionally, but it is an ineffective educational method for office workers who spend their working hours learning business English to improve their current work.

On the other hand, goFLUENT provides over 7,000 different resources, and indicating the industry and department in which the learner works and the kind of language she wants to learn will give priority to content recommended to learners through artificial intelligence. Learners will take 1:1 intensive English lesson based on this content (Figure 3).

goFLUENT also provides digital 1:1 lessons that fit the work situation of office workers to learners who do a lot of work through the web as a result of the recent pandemic (Figure 4). This is a result of a larger transformation of industry with a massive shift from classroom training/F2F to this new type of more modern, flexible and interactive lessons, whether it be for individual or group lessons. With the seamless integration of Microsoft Teams, learners can easily book their lessons or join group lessons with other learners from the same company. 


\section{Make your own training path}

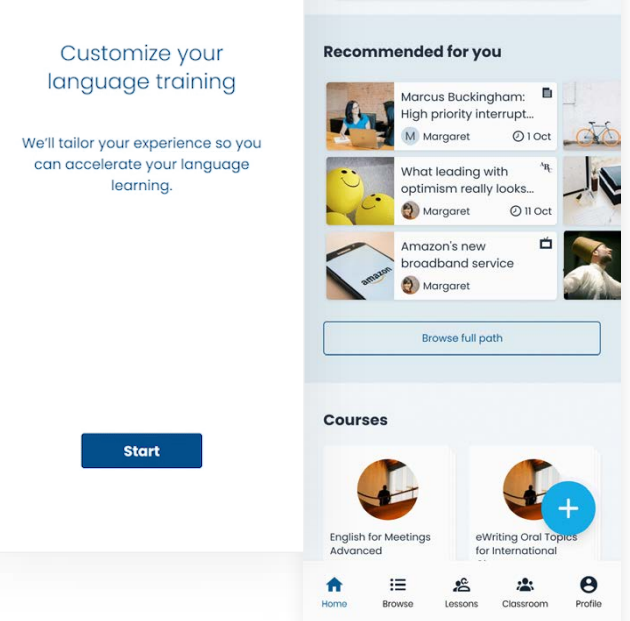

\section{Accelerate language learning even further}

Figure 3. Learners find resources that could be useful for them by recommending content that will be directly applicable to their needs. Adapted from “goFLUENT website," by goFLUENT, 2020b. Copyright 2020 by goFULENT. Reprinted with permission.

Immersive lesson experience, ltol and Group classes using Microsoft Teams

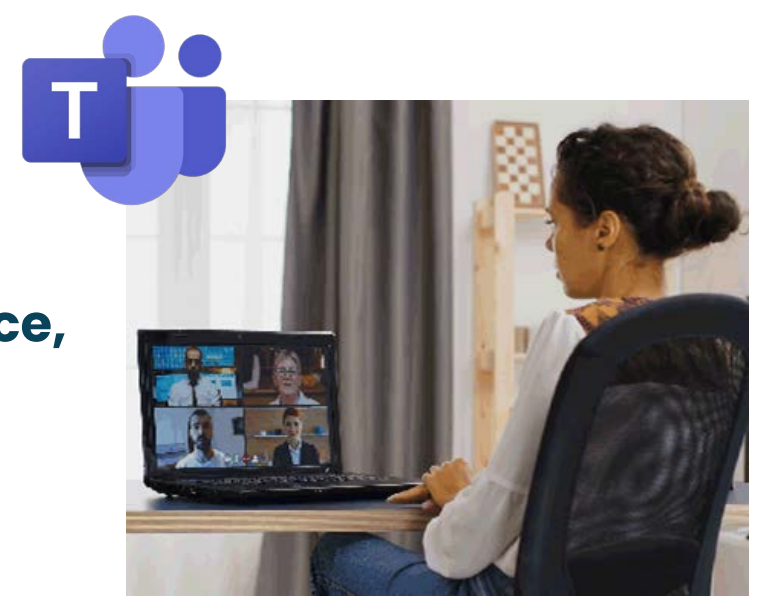

\section{Accelerate language learning even further}

Figure 4. Learners take business English lesson with digital technologies. Adapted from "goFLUENT website," by goFLUENT, 2020b. Copyright 2020 by goFULENT. Reprinted with permission.

goFLUENT provides blended learning solutions, which include eLearning, 1:1 live lesson, eWriting, virtual classrooms, leadership suites, mobile learning, and face-to-face classes to some countries (Figure 5). The key benefits of goFLUENT through blended learning include gaining confidence, saving time, and developing talent.

Office workers must be provided with continuous motivation for learning and continuous feedback for curriculum contents related to their main work so that they can continue to benefit during the learning period. This provides a digital method of 


\section{Products}

The right language learning approach varies from organization to organization, which is why we developed our solutions to flexibly cater to the varying needs and objectives of different learners. Our aim is to optimize the reach, engagement, and the efficacy of training by offering a wide range of learning opportunities for our learners.

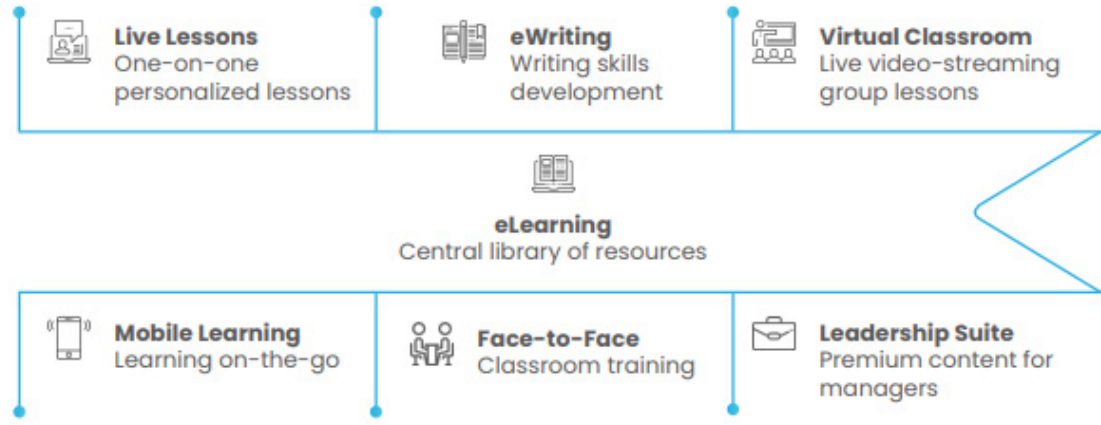

Languages We Offer

English (1) French

Figure 5. goFLUENT blended business English solutions centralized on eLearning resources. Adapted from "goFLUENT website," by goFLUENT, 2020b. Copyright 2020 by goFULENT. Reprinted with permission.

education and professional motivation with human interaction. Those who provide motivation include business English professional instructors and study consultants from their home countries who teach 1:1 live lessons and virtual classes. They are continuously confirming whether or not a personalized curriculum is provided to learners, and professionally identifying whether or not they feel the program's effects and values. All communication with learners is recorded and managed by a professional learning consultant, and the account manager (or customer success manager) who manages the company's business English projects periodically meets with a learning consultant to ensure that the project progresses smoothly, along with reporting the learners' achievement to the company every month.

\section{Background of the Program Adoption at Bayer}

Bayer Korea is a German-based global pharmaceutical and life science enterprise that has been developing a wide range of essential products for all industries for 158 years. It has about 300 subsidiary and affiliated companies, and it won first place in different medical fields. Bayer succeeded throughout its long history because of its constant pursuit of innovation. Furthermore, it strives to make a consistent challenge for innovation and change.

Since 2019, Bayer Korea has turned to digital e-learning and telephone English speaking course for workers to access foreign language education anywhere and anytime and focused on improving their business communication skills. As Bayer Koreas workers differed in levels of English language competency, interests, and business positions, 100\% customized learning courses were required. To meet these needs, Bayer Korea adopted a digital learning for the business English program, goFLUENT, which created an exclusive curriculum, including helpful content for Bayer workers, on the main webpage of their portal so that they could access it more easily (Figure 6).

Bayer Korea provided a total of 2,832 credits for 110 people for six months. Among these, 2,180 credits were used, leaving only 240 unused materials. About 77 percent of the chosen telephone English class was completed. The training path tailored to Bayer learners is provided through eLearning content, and, based on this content, after business English instructors provided 1:1 live lessons, the participation rate of classes and the rate of satisfaction toward post-class learning were both high.

\section{Effectiveness of the Program}

The following is a comparison of the education results when the fixed training path and curriculum, which were already existing, were provided, whereas the training path, which is personalized and provides flexible choices, was made possible through goFLUENT. 


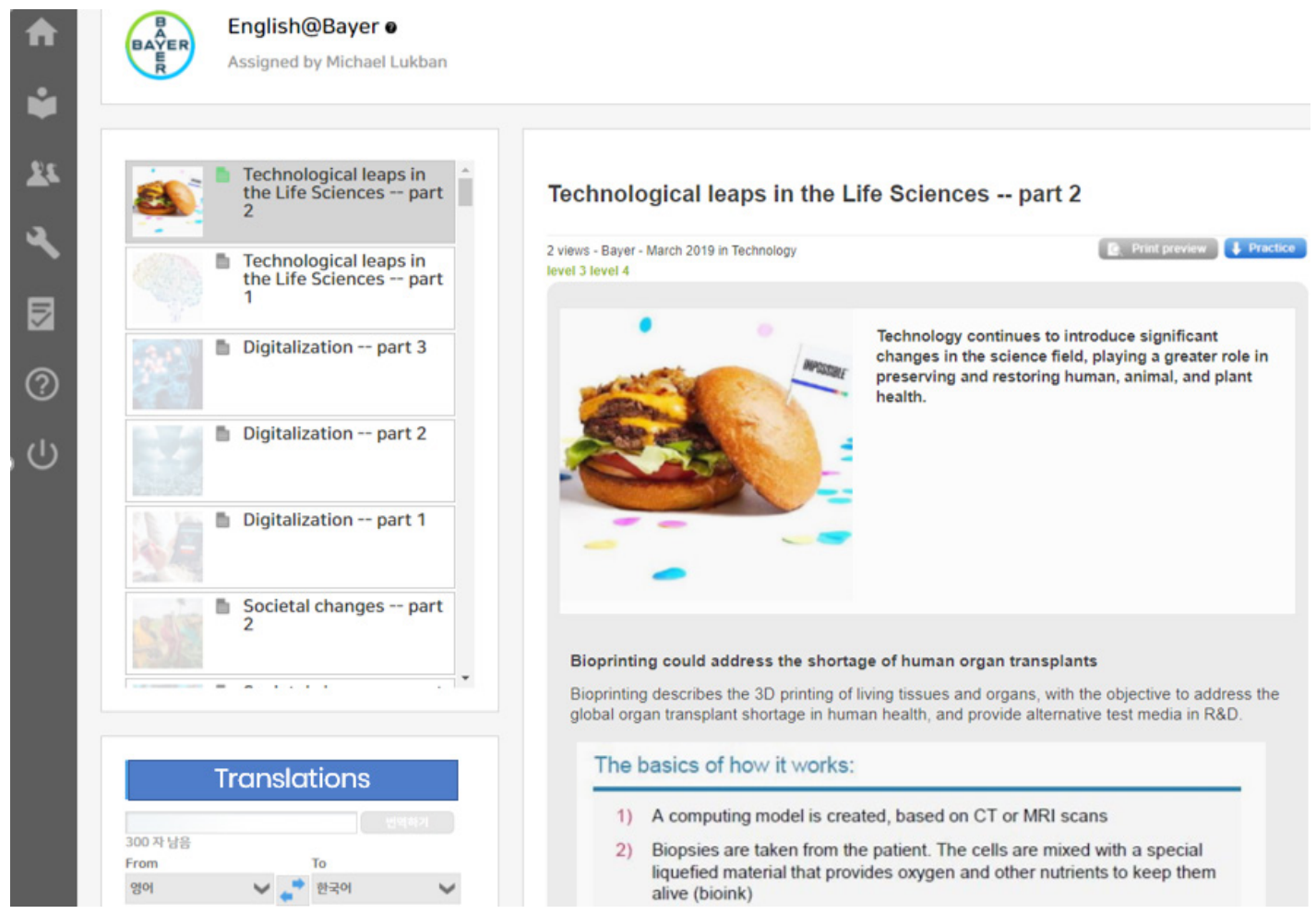

Figure 6. Customized English@Bayer business English learning portal made by goFLUENT in 2019. Adapted from "goFLUENT website," by goFLUENT, 2020b. Copyright 2020 by goFULENT. Reprinted with permission.

\section{Quantitative Statistics}

A total of 110 learners studied using the customized digital e-learning platform for Bayer Korea by English@Bayer and accomplished 15 hours of telephone English speaking course, while $75 \%$ of the 110 learners achieved the learning objective. Bayer Korea is using the goFLUENT program after the renewal of its contract in August (goFLUENT, 2020a) based on its satisfaction with goFLUENT.

The following results reflected the statistics on providing customized content to 110 learners for five months, from February to August 2020.

- Number of total 1:1 live lessons: 2,832

- Number of 1:1 live lessons: 2,180

- The rest of live lesson sessiosns: 240

In a case where an enterprise that offers e-learning content through digital e-learning, participation rate increased at a minimum of 3 times to a maximum of 10 times when work-related content was provided, compared to basic English content. The contents provided with this increased capacity of business English are related to the enterprise and the individual's scope of work. Learners, who experienced a boost in global business thinking, accounted for more than $70 \%$ of learning satisfaction and indicated more willingness to relearn.

\section{Qualitative Interviews}

The following are interviews with an HR manager and a learner regarding learning based on the results of the customized content.

\section{Interview with a Talent Manager}

The development of IT has created many digital tools to help improve business English, but, paradoxically, the development of digital technology has made analog sensibilities and emotional communication skills that move people's minds to action more important. To this end, an online learning program was required to allow employees to take lessons that fit their personal schedule rather than having to deal with offline classes, since they required workers to gather at the same place and time during work hours. While searching for a suitable program, the German headquarters learned of goFLUENT; after the evaluation, Bayer employees were provided with a 1:1 telephone English lesson (Appendix 1 for further details.)

Above all, since a training path suitable for Bayer was provided, and as classes were provided by a global business English professional education institution, contents were similar to an actual business situation. As a result, learners were able to participate passionately in the class. Industry language, business grammar, real-time news reporting, and articles were excellent, and the ability to operate business English education projects was also satisfactory. 
Interview with a Learner from the Medical Department

Although the learners received English education after making conference calls with many countries, the online education program of goFLUENT was available at any time and place without restriction. I was able to apply it directly to my work by taking the conference-call course, which is the most important part of my work. Before, it was difficult to receive detailed feedback after class while studying English, but goFLUENT made it possible. I was able to improve and make up for the mistakes I made after class because I could get accurate and quick feedback on them. The most important point is that, through the goFLUENT classes, I can talk about my thoughts and opinions freely in English during conference calls (Appendix 2 for further details.)

\section{Discussion}

\section{The Importance of Customized Digital Learning}

There is no learner in the same situation at any workplace. Every industry, department, employee, etc. has individual circumstances; that is, every enterprise and its workers have different learning conditions, needs, English levels, and learning methods; therefore, it is essential to have personalized and customized e-learning content for an effective business English learning.

When a website displays content without reflecting the interest of online consumers, $74 \%$ reported being dissatisfied. The marketing strategy of personalization, which is recognized in e-commerce, should be filtering out unnecessary content for a learner with more business-related content for workers in business. Also, it should provide content that is generally more suitable. Overly difficult content may result in a drop in confidence and the desire to study, while overly easy content may make learners think they are wasting time.

Korea regards 52 work hours as important, so rather than providing many detailed curriculums, providing business English, Skillsoft, and leadership lectures would make workers realize the values of learning. Whether we are prepared or not, digitalization of business English education has already started, and more and more enterprises will shift to $100 \%$ digitalization.

Enterprises would have a problem regarding the digitalization of business English education for global business communication. To provide business English digitally to learners without resulting in a sense of unfamiliarity, it should produce a sense of relationship with the individual and an acknowledgment of the learner's personalization along with digitalization. Therefore, when digital e-learning and personalized content are both provided, learners can study under optimal conditions, which bring loyalty to the company and satisfaction with the studies.
Table 1. Effectiveness of the programs goFLUENT provided to global companies for a year period (Unit: \%)

\begin{tabular}{lcccc}
\hline Variable & Roche & $\begin{array}{c}\text { Schneider } \\
\text { electronic }\end{array}$ & ADP & Natixis \\
\hline Gain confidence & 97 & 89 & 97 & 92 \\
Save time & & 86 & 95 & 95 \\
Grow talent & & 85 & 97 & \\
Professional training & $90+$ & 85 & 97 & 97 \\
\hline
\end{tabular}

\section{Effectiveness of Education in Other Companies}

There have also been many cases of proven effectiveness in global companies, such as Roche, Schneider Electric, ADP, Bristol-Meyers Squibb, and Natixis, based on the results of a satisfaction survey conducted on learners after providing programs of goFLUENT over a one-year period (Table 1). The indexes point to what goFLUENT is aiming for-gain confidence, save time, and grow talent. Moreover, an index to note the professionalism of the education program of goFLUENT was added.

Many companies have a unique culture. Even within the same industry group, it is difficult to bring a positive effect of conducting business English education with a fixed method of education because the members in the group are different, and the company's situation is different. Therefore, the global communication strategy, situation, challenges, budget, and leader behaviors of the company are fully studied before providing business English education to many companies. Thus, the success rate and satisfaction of business English education projects are high because companies and providers understand and proceed with the same goals and provide business English solutions accordingly (Figure 7).

\section{Conclusion}

To workers that place a high value on time, an online education with content distributed digitally in preferred places and times is highly effective and important. In particular, business foreign language learning should be provided with content from various perspectives, and repetitive learning when it is necessary. A global era is one in which it is hard for an enterprise to survive by running a business only in its country. Contents provided to improve global communication for each enterprise should be provided with the individuals' work-related content and content they are interested in along with global general knowledge. Workers spend their time productively when they feel the provided materials are aligned with their situations and needs. Thus, it leads to an extension of time and higher satisfaction toward learning, which improves business communication in 


\section{Impact}

Clients

\section{dasics}

60 gOFLUENT is a very effective language improvement solution, usable at any time and with contents that span all areas of the company. The teachers, coming from different countries in the world, all adopt the same methodology and are very professional.

- Alessandra Tanzi, HR Manager, Asics

\section{FASTIJIEB}

gOFLUENT is an extremely reliable partner of trust. The participants express a high level of satisfaction and confirm the training effectiveness thanks to the platform and customizable contents. A strong point-for us, the added value-is the back-office support with precise updates based on our needs.

- Maria Dolores Lupo, Development and Training Professional, Fastweb

\section{"subito}

goFLUENT is effective because it can be used anywhere and at any time, because it offers constantly updated and differentiated video content and articles, and because the mobile version is a valid response to the growing digital learning needs.

- Beatrice Taralla Head of HR, Subito

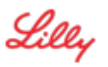

66 When I started traveling for my job, my English needs changed, so I asked the trainer to focus more on improving my fluency and improving my pronunciation. So I was the one who was deciding each time, what the goal of the lesson would be. The lessons were tailored to my needs $100 \%$. - Antonello Paliotta, Treasury and Credit Manager, Eli Lilly Italy

Figure 7. Client feedback after eLearning through goFLUENT. Adapted from "goFLUENT website," by goFLUENT, 2020b. Copyright 2020 by goFULENT. Reprinted with permission.

English. In September 2020, Bayer designated goFLUENT as a business English education provider as a result of high participation and learning performance. Likewise, Bayer Korea employees will continue to learn business English education through goFLUENT.

\section{References}

Alcala, L. (2015, January 20). 4 trends in workplace communication [Infographic]. Retrieved from https://www.cmswire.com/ $\mathrm{cms} /$ social-business/4-trends-in-workplace-communicationinfographic-027762.php

Bhat, S. (2020, March 12). Top 5 reasons why online learning is better than face-to-face learning. Retrieved from https://elearningindustry. com/reasons-why-online-learning-face-to-face-learning

Gamil, Y., \& Rahman, I. A. (2017). Identification of causes and effects of poor communication in construction industry: A theoretical review. Emerging Science Journal, 1(4), 239-247.

goFLUENT (2020a) From F2F to digital learning: A comprehensive guide to making 'The Switch.' Retrieved from https://www.gofluent. com/wp-content/uploads/sites/451/2020/04/From-F2F-to-DigitalLearning-A-Comprehensive-Guide-To-Making-The-Switch.pdf goFLUENT (2020b). goFLUENT. Retrieved from https://www. gofluent.com/us-en

Jouany, V. (2020, June 4). 10 shocking International communications stats you can't ignore. Retrieved from https://blog.smarp.com/10shocking-internal-communications-stats-you-cant-ignore

Mandelbaum, A. (2019, September 18). The important of business communication in your organization. Retrieved from https://www. smbadvisors.com/capabilities/sales-marketing-integration/insights/ the-importance-of-business-communication-in-your-organization

Pasovska, S. \& Miceski, T. (2018). Practicing proper business communication to achieve higher company performance. Proceedings of the Second International Scientific Conference on Economics and Management, EMAN 2018 (pp. 429-437). Ljubljana, Slovenia. Retrieved from http://eprints.ugd.edu.mk/20717/1/PRACTICING\%20 PROPER\%20BUSINESS\%20COMMUNICATION\%20TO\%20 ACHIEVE\%20Ljubljana\%202018.pdf

Statista. (2019, September 24). Average amount of money spent per month for online learning in South Korea as of February 2019. Retrieved from https://www.statista.com/statistics/1053533/ south-korea-online-learning-monthly-spending/

Yordanova, H. (2019, June 26). Why English is dominant business language. Retrieved from https://medium.com/@englishforward/ why-english-is-the-dominant-business-language-bc24820369b0 


\section{Appendix}

Appendix 1. Interview transcripts with a talent manager

Q: What business/HR/talent challenges and objectives did you need to address with language learning?

A: IT technology has been supporting the reduction of the language barrier in various aspects. Currently, many companies invest money in translation agencies to translate written materials. In the short run, it surely is comforting to employees if they can interpret text more easily and quickly; however, since it is a machine translator, inaccurate translations can frequently occur, an issue that cannot be ignored. Due to this lack of accuracy, employees have required a higher level of language skills than machine translation services, especially in speaking and listening situations.

Q: How critical is time efficiency when learning? Please elaborate.

A: There is a perception that online programs that substituted for offline lessons were not as efficient as offline ones. On the contrary, the fact that offline courses require all students to assemble at the same place and time refutes this approach. Switching from offline training programs to virtual ones was seemingly the most efficient decision to accommodate all of the individual's skills, room for improvement, and preference in learning method.

Q: What sets goFLUENT apart from other solutions?

A: I heard about goFLUENT from our HR headquarters in Germany. They initiated a big project, reviewing language training programs and vendors; among them, goFLUENT was one of the final top 2 companies.

Q: What were the three key products, services, or features of goFLUENT that impressed you most? Please elaborate.

A: The contents, as well as the interface, are most suited and well customized for our employees. Training sessions via phone and Skype felt similar to real business environments. Also, working on some assignments as part of a follow-up study, such as videos, articles, and grammar and vocabulary exercises, addressed my needs accordingly. A number of participants barely joined the phone training, but others were enthusiastic about learning advanced content. goFLUENT provides a one-stop service for various levels. 
Appendix 2. Interview with a learner from the medical department

Q: What is your role? Can you describe your responsibilities and the benefits you gained from digital language learning?

A: I have been working for about a year as a senior pharmacovigilance officer in the medical department of Bayer Korea. I usually have a conference call with colleagues from Bayer's global offices, and the English class of goFLUENT was conducted in a similar format. Through the conduct of regular classes, I was trained to communicate in English over the phone, helping me significantly during actual meetings. Also, videos provided by the goFLUENT program helped me become familiar with English pronunciation and the intonation of people from different English-speaking countries.

Q: What have you been able to achieve since using goFLUENT?

A: The best thing about goFLUENT's class was that I could get immediate feedback on the mistakes I made during the private class with native speakers. I communicate often using English at work, but I didn't get many opportunities to have my sentences corrected. However, with the help of the goFLUENT class, I could get some feedback from native speakers. I was able to ask them questions directly during the class. Moreover, the feedback I got could be applied to actual English-speaking situations, keeping me motivated to learn the language even more.

Q: Can you describe goFLUENT's benefits in terms of improving your confidence, learning efficiency, and/or international growth opportunities?

A: In terms of learning efficiency, goFLUENT allows me to have access to language learning resources wherever I am with whatever device I have. I no longer need to fit an existing course into my schedule. Digital learning resources can be accessed at any time of day or night, for as many hours at a time or as little as a few minutes between existing commitments. One of the most obvious benefits of using goFLUENT is being able to set my own pace. I can take it slowly with the materials I find tricky and move faster with the modules I am confident with.

Q: How long would you say it took for you to be able to achieve your language learning objectives?

A: My ultimate goal for language learning is to be able to communicate effectively with my colleagues from different countries and make more friends. I have achieved meaningful improvements through the goFLUENT program so far. Still, there were many times when my thoughts were not fully expressed as I wanted them to be. I will try to expose myself more to English-speaking situations as often as I can for the next couple of years, and I hope such practice will make me communicate better with native speakers in the near future. 